\title{
A prospective study of the use of antibiotics in the Emergency Department of a Chinese University Hospital
}

Linan Zeng, Die Hu, Imti Choonara, Dezhi Mu, Lingli Zhang, Xihong Li, Zuojie Zhang, Zhiqiang Hu and Shuyan Quan

\begin{abstract}
Background

Antibiotics are one of the most widely misused group of medicines. The aim of this study was to investigate the use of antibiotics in one of the paediatric emergency departments in China.
\end{abstract}

\section{Methods}

We performed a prospective, cross-sectional study of antibiotic use in the paediatric emergency room of West China Second University Hospital. 500 consecutive patients from March 25 to April 32013 were included. Clinical details of the patients were also collected in order to analyse antibiotic use.

\section{Results}

The median age of patients was 2 years 2 months. The five most common conditions seen in the emergency department were wheezy bronchitis, upper respiratory tract infections, tonsillitis, pneumonia and diarrhoea. 311 children (62\%) received antibiotics. The antibiotics prescribed were predominantly cephalosporins and penicillins. More than one antibiotic was used in 51 patients. $75 \%$ of the antibiotics prescribed were cephalosporins. More than three quarters of the young children with wheezy bronchitis received antibiotics. Antibiotic use for children with an upper respiratory tract infections or tonsillitis was greater than the $20 \%$ maximum recommended by the European Surveillance of Antimicrobial Consumption.

\section{Conclusion}

The majority of children attending the emergency department received antibiotics. For many of the conditions the use of antibiotics was inappropriate.

\section{Background}

Antibacterial drugs are one of the most widely used group of medicines in both general and paediatric patients.Higher country level rates of antibiotic resistance have been shown to be associated with higher antibiotic use [1]. A review of the use of antibiotics in paediatric outpatients in Canada, the USA, Australia and six European countries showed a fourfold variation in the prevalence of prescribed antibiotics. $14 \%$ of children in the UK received antibiotics whereas $52 \%$ of children in Italy received antibiotics. [2] In China, the rate of antibiotic use in paediatric outpatients was found to be considerably higher $(85 \%)$.[3]

It has been suggested that $50 \%$ of paediatric antimicrobial prescriptions are inappropriate.[4] Inappropriate use results in bacterial resistance and additionally is a waste of health resources [5,6]. Concern has previously been raised regarding the antibiotic resistance in children caused by overuse of antibiotics in China.[7,8] We 
performed a prospective, cross-sectional study of antibiotic use in the paediatric emergency room in one Chinese hospital to assess the rationality of antibiotic use. .

\section{Methods}

\section{Setting}

The setting was the West China Second University Hospital(WCSUH) emergency department. This hospital follows the national policy of antibiotic management.This hospital has a prescribing policy which classifies antibiotics as for unrestricted use, restricted use and special use.

\section{Subjects}

The subjects were 500 consecutive paediatric patients ( 0 to 18 years old) attending the emergency department (ED) between March 25 to April 3, 2013.

This study was approved by the Institutional Review Board of West China Second University Hospital.

\section{Data Collection}

Patient and medication information was collected by clinical pharmacists. To avoid influence on drug use behavior, doctors were not informed of the aim of the study. Children were classified into four groups: newborn infants (0 to 27 days), infants and toddlers (28 days to 23 months), children (2 to 11 years) and adolescents (12 to 18 years).

\section{Evaluation of Antimicrobial Use}

Antibacterial agents were classified into 13 groups according to the Anatomical Therapeutic Chemical (ATC) classification system of World Health Organization (WHO). The evaluation were based on two levels. On the hospital level, prescribing indicators were assessed according to How to Investigate Antimicrobial Use in Hospitals: Selected Indicators.[9] On the prescription level, the rational use of antibiotics was assessed in relation to: indication, medicine selection, formulation or route of administration, dose, drug combination, compatibility and allergy testing.[19] [11-18].

\section{Data management}

Data was entered into an Excel spreadsheet by one researcher (Die Hu) . Categorical data was described by frequency and proportion, while continuous data was described by mean and standard deviation(SD) or median and range. Chi-square test was conducted to test for associations between rates of antibacterial use and impact factors.

\section{Results}

\section{Patients}

Of the 500 patients, 289 were male, and 211 were female. The median age was 2 years 2 months. There were 239 (48\%) infants and toddlers and 255 (51\%) children. There were only 6 adolescents and no neonates (Table 1 ). 


\section{Antimicrobial Use}

Overall 311 children (62\%) received antibiotics. (Table 2) The mean number of antimicrobials prescribed per patient was 1.2, and the mean cost was 80.6 yuan (12.1 US dollars). More than one antibiotic was used in 51 patients. The four most common conditions seen in the ED were wheezy bronchitis, URTI, tonsillitis, and pneumonia. 120 of the 149 children with wheezy bronchitis received antibiotics. (Table 3). 76 of the 91 children (87\%) with tonsillitis and 29 of the 91 children $(25 \%)$ with an URTI also received antibiotics(Table 3). The antibiotics prescribed were predominantly cephalosporins and penicillins $(75.3 \%, 22 \%)$. No quinolones were prescribed.

Sex of patients did not influence antibiotic use $(\mathrm{P}=0.57)$, but the rate of antibiotics was significantly different between age groups. Children $(67.8 \%)$ received more antibiotics than adolescents $(16.7 \%)$, infants and toddlers $(57.8 \%)(\mathrm{P}=0.01)$.

\section{Discussion}

Over half the children attending the emergency department received antibiotics. Of particular concern was the high rates of antibiotic use for children with wheezy bronchitis and tonsillitis. Over $80 \%$ of children with either of these conditions received antibiotics. Antibiotic use for children with an URTI or tonsillitis was greater than the $20 \%$ maximum recommended by the ESAC.[10].

The main strengths of this study were that data were collected prospectively and focused on the most widely used medicines ie. antibiotics. The main limitations were that it was a single centre study and interviews were not performed with the doctors as to their reasons for prescribing antibiotics.

Many of the previous studies are over 10 years old.[20,21] A recent study in Italy showed that the introduction of guidelines on the use of antibiotics for acute otitis media did not reduce the use of antibiotics for this condition in children. [22]. A Spanish study of drug use in children in the ED focused on labelling, but suggested that over $10 \%$ prescriptions were for systemic anti-infectives [23].

Inappropriate antibiotic use is a major component of irrational drug prescribing in children. Our studies suggest that education about the rational use of antibiotics is required for health professionals within the paediatric emergency department setting.

\section{Reference}

1.Herman Goossens, Matus Ferech, Robert Vander Stichele, Monique Elseviers. Outpatient antibiotic use in Europe and association with resistance: a cross-national database study. Lancet 2005; 365: 579-872. 
2.Clavenna A, Bonati M. Differences in antibiotic prescribing in paediatric outpatients. Arch Dis Child. 2011, 96: 590-5.

3.Wang Fang-ying. Analysis of anti-bacterial drug use in outpatient paediatrics. Chin J New Drugs Clin Remedies. 2011; 30: 230-233.

4.Pichichero ME. Dynamics of antibiotic prescribing for children. JAMA. 2002; 287: 3133-3135.

5.Risk R et al. Rational prescribing in paediatrics in a resource-limited setting. Arch Dis Child. 2013; 98: 503-9.

6.Choonara I. Rational prescribing is important in all settings. Arch Dis Child. 2013; 98:720.

7.Howard DH, Scott RD. The economic burden of drug resistance. Clin Infect Dis. 2005; 41(Suppl 4): S283-6.

8.Nianjiang Wu, Lixin Wu. A survey of antibiotics use in emergency department in our hospital. Chin J Mod Drug Applic 2008; 2:110-112.

9.Strengthening Pharmaceutical Systems. 2008. How to Investigate Antimicrobial Use in Hospitals: Selected Indicators. Published for the U.S. Agency for International Development by the Strengthening Pharmaceutical Systems Program. Arlington, VA: Management Sciences for Health.

10.Adriaenssens $\mathrm{N}$ et al. European Surveillance of Antimicrobial Consumption (ESAC): disease-specific quality indicators for outpatient antibiotic prescribing. BMJ Qual Saf (accessed 21 March 2011, epub ahead of print).

11.Paediatric Formulary Committee. BNF for Children 2011-2012. London: Pharmaceutical Press, 2011.

12.The Subspecialty Group of Respiratory Diseases, the Society of Pediatrics, Chinese Medical Association, Editorial Board of Chinese Journal of Pediatrics. Guideline for diagnosis and treatment of chronic cough in children, Chin J Pediatr, 2008, 46: 140-147.

13.The Subspecialty Group of Respiratory Diseases, the Society of Pediatrics, Chinese Medical Association, the Editorial Board of Chinese Journal of Pediatrics. Guideline for management of community acquired pneumonia in children (Volume 1). Chin J Pediatr, 2007, 45: 83-90.

14.The Subspecialty Group of Respiratory Diseases, the Society of Pediatrics, Chinese Medical Association, the Editorial Board of Chinese Journal of Pediatrics. Guideline for management of community acquired pneumonia in children (Volume 2). Chin J Pediatr, 2007, 45: 223-230. 15.Editorial Board of Chinese Journal of Otorhinolaryngology Head and Neck Surgery, the Subspecialty Group of Pediatrics, the Society of Otorhinolaryngology Head and Neck Surgery, Chinese Medical Association. Guideline for diagnosis and treatment of otitis media in children (Draft). Chin J Otorhinolaryngol Head Neck Surg, 2008, 43: 884-885. 
16.The Subspecialty Group of Respiratory Diseases, the Society of Pediatrics, Chinese Medical Association, the Editorial Board of Chinese Journal of Pediatrics. Guideline for rational use of antibiotics in acute respiratory infections (Volume 1). Chin J Pediatr, 2000, 15: 444-446.

17.The Subspecialty Group of Respiratory Diseases, the Society of Pediatrics, Chinese Medical Association, the Editorial Board of Chinese Journal of Pediatrics. Guideline for rational use of antibiotics in acute respiratory infections (Volume 2). Chin J Pediatr, 2001, 39: 379-383.

18.Wang Y, Wan CM. Guideline for diagnosis and treatment of acute fever of unknown etiology in Chinese children aged 0 to 5. Chin J Evid Based Pediatr, 2008, 3: 449-457

19.Hospital prescription Review Management (trial). Available from:

http://www.gov.cn/gzdt/2010-03/04/content_1547080.htm

20.Steinmann K, Babl FE. Antibiotic prescribing rates for acute otitis media in a paediatric emergency department. J Paed Child Health. 2006; 42: 204-205.

21.Thorpe JM, Smith SR, Trygstad TK. Trends in emergency antibiotic prescribing for acute respiratory tract infections. Ann Pharmacother. 2004; 38: 928 - 935.

22.Palma $\mathrm{S}$ et al. The impact of the Italian guidelines on antibiotic prescription practices for acute otitis media in a paediatric emergency setting. Ital J Ped. 2015; 41:37.

23. Morales-Carpi C et al. Drug utilization and off-label drug use among Spanish emergency room paediatric patients. Eur J Clin Pharmacol 2010; 66: 315-320.

Table 1 Characteristic of Patients

\begin{tabular}{lc}
\hline Characteristics of patient & \\
\hline Sex & $211(42.2 \%)$ \\
$\quad$ Female, $\mathrm{n}(\%)$ & $289(57.8 \%)$ \\
$\quad$ Male, $\mathrm{n}(\%)$ & 780.4 \\
Median Age, $\mathrm{d}$ & $18.8 \pm 4.0$ \\
Average weight, $\mathrm{Kg}$ & \\
Age group & $0(0.0 \%)$ \\
$\quad$ newborn infants (0 to 27 days), $\mathrm{n}(\%)$ & $239(47.8 \%)$ \\
$\quad$ infants and toddlers (28 days to 23 months), $\mathrm{n}(\%)$ & $255(51.0 \%)$ \\
$\quad$ children (2 to 11 years), $\mathrm{n}(\%)$ & $6(1.20 \%)$ \\
\hline
\end{tabular}


Table 2 The Overall Pediatric Antimicrobial Use in Emergency Room

\begin{tabular}{|c|c|c|}
\hline & Indicator & Results \\
\hline \multirow[t]{5}{*}{$\begin{array}{l}\text { Hospital } \\
\text { Indicators }\end{array}$} & $\begin{array}{l}\text { 1. Existence of standard treatment guidelines } \\
\text { (STGs) for infectious diseases }\end{array}$ & None \\
\hline & $\begin{array}{l}\text { 2. Existence of an approved hospital formulary list or } \\
\text { essential medicines list (EML) }\end{array}$ & Yes \\
\hline & $\begin{array}{l}\text { 3. Availability of a set of key antimicrobials in the } \\
\text { hospital stores on the day of the study }\end{array}$ & $100.0 \%$ \\
\hline & $\begin{array}{l}\text { 4. Average number of days that a set of key } \\
\text { antimicrobials is out of stock }\end{array}$ & $0 d$ \\
\hline & $\begin{array}{l}\text { 5. Expenditure on antimicrobials as a percentage of } \\
\text { total hospital medicine costs }\end{array}$ & $15.5 \%$ \\
\hline \multirow[t]{5}{*}{$\begin{array}{l}\text { Prescribing } \\
\text { Indicators }\end{array}$} & $\begin{array}{l}\text { 6. Percentage of patients with one or more } \\
\text { antimicrobials prescribed }\end{array}$ & $62.2 \%$ \\
\hline & $\begin{array}{l}\text { 7. Average number of antimicrobials prescribed per } \\
\text { patient in which antimicrobials were prescribed }\end{array}$ & 1.2 \\
\hline & $\begin{array}{l}\text { 8. Percentage of antimicrobials prescribed } \\
\text { consistent with the hospital formulary list }\end{array}$ & $100.0 \%$ \\
\hline & $\begin{array}{l}\text { 9. Average cost of antimicrobials prescribed per } \\
\text { patient in which antimicrobials were prescribed }\end{array}$ & 80.6 yuan \\
\hline & $\begin{array}{l}\text { 10. Percentage of antimicrobials prescribed by } \\
\text { generic name }\end{array}$ & $100.0 \%$ \\
\hline
\end{tabular}


Table 3 Ratio of Antimicrobial Use

\begin{tabular}{|c|c|c|}
\hline & $\begin{array}{l}\text { Num. of } \\
\text { prescribe }(n)\end{array}$ & Ratio (\%) \\
\hline cephalosporins & 284 & 75.3 \\
\hline Cefazolin & 179 & 63.0 \\
\hline Cefdinir & 72 & 25.4 \\
\hline Cefaclor & 11 & 3.9 \\
\hline Ceftazidime & 5 & 1.8 \\
\hline Cefathiamidine & 5 & 1.8 \\
\hline Cefixime & 4 & 1.4 \\
\hline Cefoxitin & 3 & 1.1 \\
\hline Cefoperazone and Tazobactam & 3 & 1.1 \\
\hline Ceftriaxone & 2 & 0.7 \\
\hline penicillins & 83 & 22.0 \\
\hline Mezlocillin and sulbactam & 73 & 88.0 \\
\hline Oxacillin & 7 & 8.4 \\
\hline Penicillin & 2 & 2.4 \\
\hline Ampicillin & 1 & 1.2 \\
\hline macrolides & 6 & 1.6 \\
\hline Azithromycin & 6 & 100.0 \\
\hline other beta-lactam antibacterials & 2 & 0.5 \\
\hline Aztreonam & 2 & 100.0 \\
\hline aminoglycoside antibacterials & 1 & 0.3 \\
\hline other antibacterials & 1 & 0.3 \\
\hline
\end{tabular}

